\title{
Efeito da urina de vaca no estado nutricional da alface ${ }^{1}$
}

\author{
Nelson Licínio C de Oliveira ${ }^{2}$, Mário Puiatti, Ricardo Henrique Silva Santos, Paulo Roberto Cecon ${ }^{4}$, \\ Aline da Silva Bhering 5
}

\section{RESUMO}

Existem diversos relatos da utilização da urina de vaca em hortaliças, todavia sua eficácia carece de comprovação. Objetivou-se avaliar o efeito da urina de vaca no estado nutricional da alface. O experimento foi constituído de 12 tratamentos, esquema de parcelas subdivididas, em blocos ao acaso, com quatro repetições. Nas parcelas foram alocadas as vias de aplicação (solo ou foliar) e nas subparcelas as concentrações das soluções $(0,00 ; 0,25 ; 0,50 ; 0,75$; 1,00 e 1,25\% v/v). Aplicou-se $60 \mathrm{~mL}$ de solução/planta, divididos em cinco aplicações de 5; 5; 10; 20 e $20 \mathrm{~mL} / \mathrm{planta}$, aos 7, 14, 21, 28 e 35 após o transplante, respectivamente. Durante o ciclo avaliou-se o índice SPAD e na colheita a massa da matéria seca de cabeça (MSCA) e os teores de N, P, K, Ca, Mg, S, Na, Zn, Fe, Mn, Cu e B na matéria seca das folhas (MSF), caule (MSC) e raízes (MSR). Em ambas as vias de aplicação o índice SPAD apresentou incremento linear às concentrações e resposta quadrática ao longo do tempo. A MSCA teve comportamento linear às concentrações, com aumento de 25,9 e 35,4\% nas aplicações via foliar e solo, respectivamente. Não houve efeito de concentrações sobre teores de nutrientes na MSF e MSC. Na MSR, via solo, os teores de P e K apresentaram pontos de máximo enquanto $\mathrm{Fe}$ e Mn de mínimo; o $\mathrm{Na}$ apresentou incremento linear às concentrações via foliar. Os efeitos da urina sobre o crescimento da alface provavelmente são devidos a fatores outros que não somente a quantidade de nutrientes veiculados nas soluções.

Palavras-chave: Agricultura orgânica, Lactuca sativa L., nutrição de plantas, sistema de cultivo.

\begin{abstract}
\section{Effect of cow urine on the nutritional status of lettuce}

There are reports of the use of cow urine in vegetable crops, but its efficacy needs to be confirmed. This work aimed to evaluate the effect of cow urine on the nutritional status of lettuce. The experiment consisted of 12 treatments arranged in a split-plot design and four randomized blocks. The ways of application (soil or foliar) were allocated in plots while the subplots consisted of solution concentrations $(0.00 ; 0.25 ; 0.50 ; 0.75 ; 1.00$ and $1.25 \% \mathrm{v} / \mathrm{v})$. It was applied $60 \mathrm{~mL}$ of solution/plant, divided into five applications of $5 ; 5 ; 10 ; 20$ and $20 \mathrm{~mL} /$ plant, at 7, 14, 21, 28, and 35 days after transplant, respectively. The SPAD index was evaluated during the crop cycle. At harvest it was determined the head dry matter (HDM) and the contents of N, P, K, Ca, Mg, S, Na, Zn, Fe, Mn, Cu and B in the dry matter of leaves (DML), stems (DMS) and roots (DMR). For both ways of application, the SPAD index showed a linear increase in response to
\end{abstract}

Rev. Ceres, Viçosa, v. 57, n.4, p. 506-515, jul/ago, 2010 
concentrations and a quadratic response over time. HDM presented a linear response to concentrations, with increases of 25.9 and $35.4 \%$ in the foliar and soil applications respectively. No effect of concentrations was observed on nutrient contents of DML and DMS. For DMR, with soil application, there was a maximum point for $\mathrm{P}$ and $\mathrm{K}$ and minimum for $\mathrm{Fe}$ and $\mathrm{Mn}$; $\mathrm{Na}$ showed a linear increase in response to concentrations with foliar application. The effects of urine solutions on lettuce growth may be caused by other factors than the amounts of nutrients present in the solutions.

Key words: Lactuca sativa L., crop system, plant nutrition, organic agriculture.

\section{INTRODUÇÃO}

Dentre as hortaliças folhosas, a alface (Lactuca sativa L.) é a de maior consumo e valor comercial no mundo, podendo ser utilizada em saladas cruas e em sanduíches (Lopes et al., 2005). No Brasil, ela é cultivada, tradicionalmente, por pequenos produtores, constituindo-se, dessa forma, em cultura de grande importância econômica e social (Villas Boas et al., 2004).

Apesar de absorver quantidades relativamente pequenas de nutrientes, em comparação às outras culturas, a planta de alface pode ser considerada exigente em nutrientes, devido ao ciclo cultural curto (Katayama, 1993). Em razão do produto comercial da alface ser as folhas, a adubação nitrogenada é fundamental em razão do $\mathrm{N}$ proporcionar folhas tenras e suculentas. Dentre os micronutrientes, os que mais afetam a cultura, em termos de produção de massa e formação de cabeça, são $\mathrm{Cu}$, Mo e B (Katayama, 1993).

A urina de vaca pode ser considerada um subproduto da atividade pecuária, além de amplamente disponível em muitas propriedades rurais. Por ser rica em elementos minerais, considera-se que essa forneça nutrientes e outras substâncias benéficas às plantas a custo reduzido; além disso, seu uso não causa risco à saúde de produtores e consumidores, estando praticamente pronta para uso, bastando apenas acrescentar água (PESAGRO-RIO, 2002). Outro aspecto importante é o de permitir a integração das atividades da pecuária e da horticultura, podendo proporcionar diminuição do custo de produção das culturas, devido ao menor gasto com adubos (PESAGRO-RIO, 2002; Gadelha et al., 2003).

Resultados positivos da urina de vaca em crescimento de plantas têm sido relatados em trabalhos de pesquisas com os culturas de alface e pimentão. Em alface, a aplicação no solo de $20 \mathrm{~mL}$ por planta de solução de urina de vaca na concentração de $0,86 \%$ proporcionou acréscimo de 10,3\% na massa da matéria fresca das plantas (Gadelha et al., 2003). Em pimentão, pulverizações semanais de soluções de urina $(0$ a 5,0\%) a partir de 15 dias após o transplante até a penúltima colheita proporcionou aumento linear na produção de frutos (Oliveira et al., 2003).

Apesar de ser considerada com o recurso alternativo para nutrição de plantas, ativação metabólica e controle de pragas e doenças (PESAGRO-RIO, 2002; Boemeke, 2002; Achliya et al., 2004) e do fato de horticultores já estarem utilizando a urina de vaca em seus cultivos, a confirmação e compreensão dos seus efeitos sobre o crescimento das plantas ainda requerem maior aprofundamento científico.

Este trabalho objetivou avaliar o efeito de concentrações de urina de vaca aplicada via foliar ou solo sobre o crescimento e os teores de N, P, K, Ca, Mg, S, Na, Zn, Fe, $\mathrm{Mn}, \mathrm{Cu}$ e B na matéria seca de folhas, caule e raízes de alface em cultivo orgânico.

\section{MATERIAL E MÉTODOS}

O experimento foi realizado no Departamento de Fitotecnia da Universidade Federal de Viçosa (UFV), no período de 13/01 a 22/03/2006, com alface cultivar Regina 2000, cultivada utilizando-se práticas orgânicas, em ambiente protegido. Esse ambiente constituiu-se de casa de vegetação tipo capela, com 10,4 x 16,0 m; pé-direito de 2,0 m; altura do vão central de 3,30 m; e cobertura de filme de polietileno aditivado de baixa densidade, de $150 \mu \mathrm{m}$ de espessura, com as faces frontais e laterais abertas.

Durante o período experimental, as temperaturas do ar e do solo e a umidade relativa do ar foram registradas em termo-higrômetros digital (modelo HT-208), colocados à altura do dossel das plantas e sensor a $15 \mathrm{~cm}$ de profundidade no solo. As médias das temperaturas mínimas e máximas do ar foram de 17,5 e $41,6{ }^{\circ} \mathrm{C}$; do solo de 22,5 e $36,8^{\circ} \mathrm{C}$; e a umidade relativa do ar de 30 e $97 \%$, respectivamente.

Utilizaram-se canteiros com 1,0 m de largura, laterais de alvenaria, dispostos no sentido leste-oeste, preenchidos com um Argissolo Vermelho-Amarelo Câmbico de classificação textural argilo-arenosa, retirado do local original na profundidade de $10 \mathrm{~cm}$, com as seguintes características químicas: $\mathrm{pH}$ em água $(1: 2,5)=5,2 ; \mathrm{P}=$ $320,0 \mathrm{mg} \mathrm{dm}^{-3}$ e P-rem = 27,1 $\mathrm{mg} \mathrm{L}^{-1}$; em mg dm${ }^{-3}: \mathrm{K}=48,0 ; \mathrm{Na}$ $=12,0$ e S $=64,4 ; \mathrm{em} \mathrm{cmol}_{\mathrm{c}} \mathrm{dm}^{-3}: \mathrm{Ca}^{+2}=4,9 ; \mathrm{Mg}^{+2}=0,5 ; \mathrm{Al}^{+3}=$ 0,$4 ; \mathrm{H}+\mathrm{Al}=11,1 ; \mathrm{SB}=5,6 ; \mathrm{CTC}_{(\mathrm{t})}=6,0 ; \mathrm{CTC}_{(\mathrm{T})}=16,6 ; \mathrm{em}$ $\%: \mathrm{V}=33,0 ; \mathrm{m}=7,0$ e ISNa $=0,9 ; \mathrm{MO}=4,8 \mathrm{dag} \mathrm{kg}^{-1} ; \mathrm{em}$ $\mathrm{mg} \mathrm{dm}{ }^{-3}: \mathrm{Zn}=20,3 ; \mathrm{Fe}=157,2 ; \mathrm{Mn}=40,8 ; \mathrm{Cu}=0,8 ;$ e B = 2,3 . 
Procedeu-se a correção do solo com calcário dolomítico, PRNT 100\%, com base no método da neutralização do $\mathrm{Al}^{3+}$ e da elevação dos teores de $\mathrm{Ca}^{2+} \mathrm{e}$ $\mathrm{Mg}^{2+}$ e recomendação para a cultura (Alvarez \& Ribeiro, 1999). O calcário foi incorporado ao solo 30 dias antes do transplante das mudas, seguido de irrigações diárias. Cinco dias antes do transplante, procedeu-se a adubação com esterco de bovino curtido na quantidade de $3,2 \mathrm{~kg} \mathrm{~m}^{-2}$ (em massa de matéria seca), com as seguintes características: pH em água $(1: 2,5)=8,5 ; \mathrm{em} \%: \mathrm{N}=2,4 ; \mathrm{P}=0,8 ; \mathrm{K}=0,9$; $\mathrm{Ca}^{+2}=1,9 ; \mathrm{Mg}^{+2}=0,7 ; \mathrm{S}=0,5 ; \mathrm{C} . \mathrm{O}=15,3 ; \mathrm{C} / \mathrm{N}=6,4 ; \mathrm{em}$ $\mathrm{mg} \mathrm{dm}^{-3}: \mathrm{Zn}=370,0 ; \mathrm{Fe}=12.891 ; \mathrm{Mn}=182,7 \mathrm{Cu}=66,0 ; \mathrm{B}$ $=41 ; \mathrm{Cd}=0,0 ; \mathrm{Pb}=56,0 ; \mathrm{Ni}=1,0$ e $\mathrm{Cr}=0,0$; e teor de umidade $=43,1 \%$.

O experimento, constituído de 12 tratamentos, foi conduzido no esquema de parcelas subdivididas, delineamento em blocos ao acaso, com quatro repetições. Nas parcelas foram alocadas as vias de aplicação das soluções de urina de vaca (solo ou foliar) e nas subparcelas, as concentrações das soluções de urina de vaca $(0,00 ; 0,25 ; 0,50$; $0,75 ; 1,00$; e $1,25 \% \mathrm{v} / \mathrm{v})$. A unidade experimental foi constituída por quatro fileiras de $1,75 \mathrm{~m}$ de comprimento, com as plantas espaçadas de $0,25 \times 0,25 \mathrm{~m}$. Considerou-se como área útil aquela compreendida pelas seis plantas centrais das duas fileiras centrais.

As mudas foram obtidas em ambiente protegido, em bandejas de poliestireno expandido de 200 células, preenchidas com substrato constituído de mistura da terra utilizada para enchimento dos canteiros de cultivo e de esterco de gado bovino curtido na proporção 1:1 (v:v). O substrato foi submetido à solarização sob plástico transparente de $150 \mu \mathrm{m}$ por sete dias antes da semeadura. O transplante foi realizado aos 25 dias após a semeadura, quando as mudas apresentavam quatro folhas definitivas.

A urina utilizada foi coletada de vacas em lactação, de rebanho leiteiro do Departamento de Zootecnia/UFV, realizando-se a coleta da urina de 15 vacas de plantel de sanidade comprovada em único dia. A urina foi armazenada em recipiente plástico desinfectado, que foi mantido vedado, e armazenado em abrigo. Iniciou-se a sua utilização no quarto dia de armazenamento, quando uma amostra foi analisada, apresentando a seguinte composição $\left(\mathrm{em} \mathrm{mg} \mathrm{L}^{-1}\right.$ ): $\mathrm{N}=12.600,0 ; \mathrm{P}=97,8 ; \mathrm{K}=2.666,0 ; \mathrm{Ca}=5,0$; $\mathrm{Mg}=330,0 ; \mathrm{S}=45,0 ; \mathrm{Fe}=4,0 ; \mathrm{Mn}=4,0 ; \mathrm{Cu}=2,0 ; \mathrm{Zn}=8,0$; $\mathrm{B}=110,0 ; \mathrm{Na}=2.000,0 ; \mathrm{Co}=6,0 ; \mathrm{Mo}=9,0 ; \mathrm{Al}=2.900,0 ; \mathrm{Cl}$ $=1.700,0 ;$ e densidade $=1,0 \mathrm{~g} \mathrm{~mL}^{-1}$.

As concentrações das soluções dos tratamentos foram obtidas por diluição da urina em água destilada aplicando-se, em cada via de aplicação e concentração, o volume de $60 \mathrm{~mL}$ de solução planta ${ }^{-1}$. Esse volume foi dividido em cinco aplicações semanais, iniciando-se uma semana após o transplante das mudas, aplicando-se, res- pectivamente, $5 ; 5 ; 10 ; 20$; e $20 \mathrm{~mL}$ de solução planta $^{-1}$ por vez. Na dose $0,0 \%$ somente foi aplicada água destilada. Esses volumes de soluções aplicados foram definidos diante do crescimento das plantas. Considerando-se a aplicação de $60 \mathrm{~mL}$ planta $^{-1}$ de solução de urina e população de 128.000 plantas ha ${ }^{-1}$, as quantidades de nutrientes aplicados, em $\mathrm{g} \mathrm{ha}^{-1}$, na maior concentração de urina de vaca $(1,25 \%)$, foram de: $\mathrm{N}=1.209,60 ; \mathrm{P}=9,47 ; \mathrm{K}=255,87 ; \mathrm{Ca}=$ 0,$48 ; \mathrm{Mg}=31,68 ; \mathrm{S}=4,32 ; \mathrm{Fe}=0,38 ; \mathrm{Mn}=0,38 ; \mathrm{B}=10,56$; $\mathrm{Cu}=0,19 ; \mathrm{Zn}=0,77 ; \mathrm{Na}=192,00 ; \mathrm{Cl}=163,20 ; \mathrm{Co}=0,58 ;$ $\mathrm{Mo}=0,86 ; \mathrm{e} \mathrm{Al}=278,40$. Na aplicação via solo, a solução foi vertida ao redor das plantas, sem entrar em contato com a sua parte aérea, quando, via foliar, se utilizou bomba spray manual, evitando-se o escorrimento da solução das folhas para o solo e deriva da solução para parcelas vizinhas.

Foram realizadas irrigações por gotejamento utilizando-se fita autocompensada com emissores espaçados de $0,25 \mathrm{~m}$ e vazão de $3,0 \mathrm{~L} \mathrm{~h}^{-1}$. O controle da lâmina de água a ser aplicada baseou-se no balanço de água no solo com uso de tensiômetros instalados a $15 \mathrm{~cm}$ de profundidade.

Durante o ciclo, semanalmente, iniciando-se aos sete dias após o transplante, foram realizadas seis avaliações do estado de $\mathrm{N}$, por via indireta, utilizando-se o clorofilômetro SPAD - 502 (Minolta Chlorophyll Meter), em três plantas da área útil escolhidas aleatoriamente. As medições foram realizadas entre 7 e 10 horas, na primeira folha expandida, do ápice para a base da planta, tomandose três medidas, duas nos bordos laterais e uma na extremidade apical de cada folha.

Aos 46 dias após o transplante, com as plantas no ponto de comercialização, procedeu-se a colheita de três plantas da área útil. Depois de lavados e enxutos, folhas, caule e raízes foram submetidos, separadamente, à secagem em estufa com ventilação forçada a $65 \mathrm{C}$, até massa constante gerando as massas de matéria seca de cabeça (MSCA), folhas (MSF), caule (MSC) e raiz (MSR). Nessas, foram determinados os teores de $\mathrm{N}, \mathrm{P}, \mathrm{K}, \mathrm{Ca}, \mathrm{Mg}, \mathrm{S}$, $\mathrm{Na}, \mathrm{Zn}, \mathrm{Fe}, \mathrm{Mn}, \mathrm{Cu}$ e B. A extração do $\mathrm{N}$ total foi realizada com ácido sulfúrico e a dosagem por titulação com $\mathrm{HCl}$ 0,1 N. Para P, K, Ca, Mg, S, Na, Zn, Fe, Mn e Cu, utilizouse extração nitroperclórica, relação $1 / 4$; o B foi extraído por calcinação em mufla a $550^{\circ} \mathrm{C}$; P, S e B foram dosados por espectrocolorimetria; $\mathrm{K}$ e $\mathrm{Na}$ por fotometria de chama e $\mathrm{Ca}, \mathrm{Mg}, \mathrm{Zn}, \mathrm{Cu}, \mathrm{Fe}$ e $\mathrm{Mn}$ por espectrofotometria de absorção atômica (Silva, 1999).

Os dados obtidos foram submetidos à análise de variância. Independentemente da significância da interação, procedeu-se o seu desdobramento para todas as características. As médias do fator qualitativo (vias de aplicação) foram comparadas pelo teste de Tukey a 5\% de probabilidade. Para o fator quantitativo (concentrações de urina), procedeu-se a análise de regressão, sendo os 
modelos escolhidos com base na significância dos coeficientes de regressão, utilizando-se o teste $t$, adotando o nível de 1,5 e $10 \%$ de probabilidade, no coeficiente de determinação $\left(\mathrm{R}^{2}\right)$ e no fenômeno biológico em estudo.

\section{RESULTADOS E DISCUSSÃO}

A massa de matéria seca da cabeça (MSCA) apresentou aumento linear com o incremento das concentrações de urina tanto aplicada via folha $\left(\mathrm{v}=5,3515+1,1128 * \mathrm{C} ; \mathrm{r}_{2}\right.$

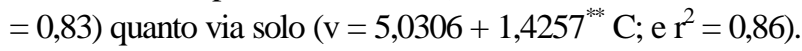
A aplicação via folha resultou em incremento na MSCA de $25,98 \%$ (de 5,35 para 6,74) e via solo de $35,38 \%$ (de 5,03 para $6,81 \mathrm{~g} /$ planta) em relação à testemunha.

Durante o ciclo, o índice SPAD, em cada avaliação, aumentou linearmente com o incremento das concentrações de urina aplicadas tanto via solo quanto foliar (Figura 1 A e B). Cada unidade de aumento na concentração de urina promoveu incremento no índice SPAD de 0,51 e 0,64 unidade para aplicações vias solo e foliar, respectivamente. Ao longo dos dias após o transplante, obtiveram-se respostas quadráticas às concentrações das soluções aplicadas, tanto via solo quanto via foliar, com unidades SPAD máximas estimadas obtidas no $46^{\circ}$ e $44^{\circ}$ dias, respectivamente.

$\mathrm{O}$ teor de clorofila tem sido utilizado como indicador para a diagnose do estado nutricional de $\mathrm{N}$ das plantas, tornando-se eficaz para prognosticar a necessidade de $\mathrm{N}$ pelas culturas (Guimarães et al., 1999; Argenta et al., 2001 a; Fontes, 2001; Neves et al., 2005), em razão do teor de clorofila da folha ter correlação positiva com o teor de $\mathrm{N}$ na planta (Guimarães et al., 1999; Argenta et al., 2001b).

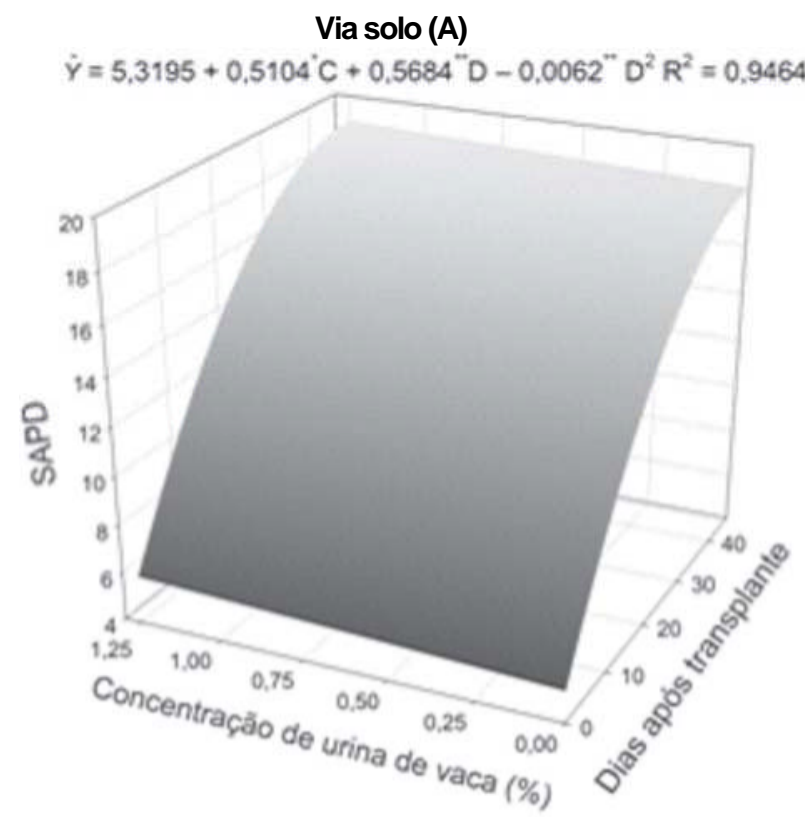

Essa correlação deve-se ao fato de 50 a $70 \%$ do $\mathrm{N}$ total das folhas ser integrante de enzimas presentes nos cloroplastos (Chapman \& Barreto, 1997).

Em alface Elisa cultivada com compostos com concentrações variáveis de $\mathrm{N}$, também foram obtidos maiores índice SPAD e massa de matérias fresca e seca da parte aérea em plantas cultivadas com composto de feijão refletindo melhor estado nutricional de N (Villas Boas et al., 2004).

Neste trabalho, não houve efeito de concentrações de urina sobre o teor de $\mathrm{N}$ na MSF tanto aplicada via solo quanto via foliar. Os teores foliares médios foram de 2,76 e 2,93 dag kg ${ }^{-1}$, respectivamente para as duas formas de aplicação. Entretanto, plantas que receberam solução de urina de vaca via foliar apresentaram maior teor de $\mathrm{N}$ na MSF em relação à aplicação via solo, sendo o aumento significativo somente na concentração de 1,0\% (Tabela 1).

As formas de $\mathrm{N}$ mais presentes na urina de bovinos adultos são, principalmente, ureia e amônio, as quais ocorrem com a grande variação em suas concentrações em função da alimentação animal (Ferreira, 1995). A ureia pode representar $75 \%$ de N-total da urina de bovinos (Jarvis et al., 1989). A passagem da ureia através da cutícula dos vegetais é mais rápida que a de outros compostos e nutrientes, e aumenta com a concentração, mas não proporcionalmente, sugerindo que essa passagem não seja por difusão simples, mas por difusão facilitada (Faquin, 1994). Admite-se que a ureia possa romper ligações químicas entre os componentes da cutícula e, além disso, promover aumento na permeabilidade da membrana celular (Malavolta, 1980).

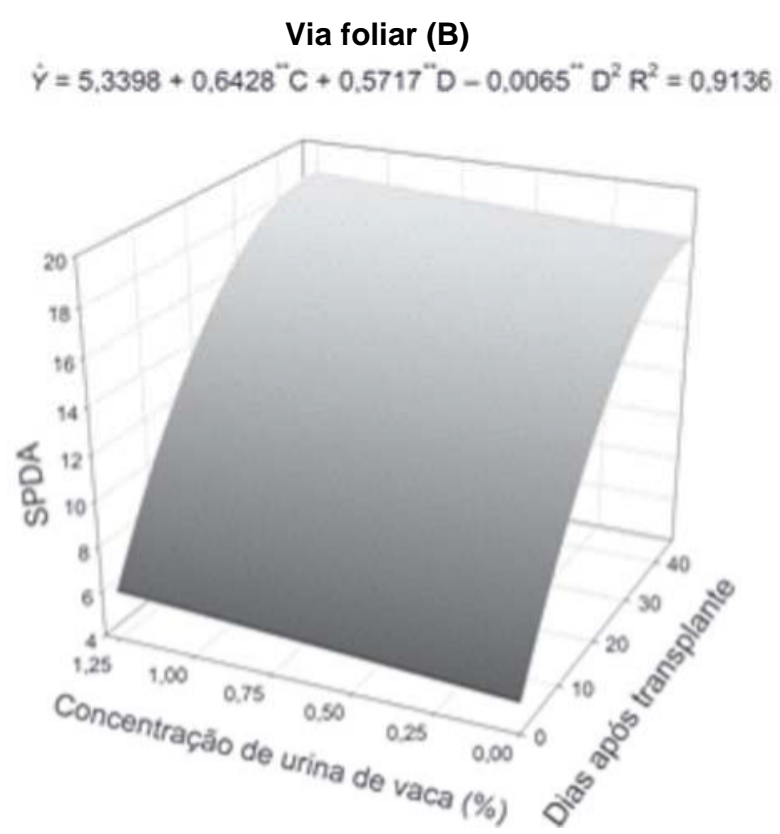

Figura 1 - Estimativa da leitura SPAD em razão da concentração de soluções de urina de vaca (C) e de dias após o transplante (D) aplicadas vias solo (A) e foliar (B) em alface 'Regina 2000'.** e *: Significativo, respectivamente, a 1 e $5 \%$ de probabilidade. 
Apesar de não ter havido efeito de concentrações de urina sobre o teor de $\mathrm{N}$ na MSF, foram observados aumentos do índice SPAD e da MSCA na aplicação das soluções tanto via foliar quanto via solo. Assim sendo, o efeito da urina de vaca pode ter sido direto fornecendo $\mathrm{N}$ para as plantas e de indireto estimulando o crescimento da planta. A falta de resposta do teor de $\mathrm{N}$ na MSF às concentrações aplicadas pode ser devida ao efeito de di-

Tabela 1 - Valores médios dos teores de nitrogênio $(\mathrm{N})$, fósforo $(\mathrm{P})$, potássio $(\mathrm{K})$, cálcio $(\mathrm{Ca})$, magnésio $(\mathrm{Mg})$, enxofre $(\mathrm{S})$ e sódio (Na)em dag kg ${ }^{-1}$ na matéria seca de folhas, caule e raiz da alface 'Regina 2000' em razão de concentração de soluções de urina de vacaaplicadas vias solo e foliar

\begin{tabular}{|c|c|c|c|c|c|c|c|c|c|c|}
\hline \multirow{2}{*}{ Elementos } & \multirow{2}{*}{\multicolumn{2}{|c|}{$\begin{array}{c}\text { Parte da } \quad \text { Via de } \\
\text { planta aplicação } \\
\end{array}$}} & \multicolumn{6}{|c|}{ Concentração da solução de urina de vaca (\%) } & \multirow{4}{*}{$\begin{array}{l}\mathbf{C V} \\
(\%) \\
2,79\end{array}$} & \multirow{4}{*}{$\begin{array}{l}\mathbf{C V}^{2} \\
(\%) \\
6,51\end{array}$} \\
\hline & & & \multirow{3}{*}{$\begin{array}{c}\mathbf{0 , 0 0} \\
2,72 \mathrm{a} \\
2,84 \mathrm{a} \\
\end{array}$} & \multirow{3}{*}{$\begin{array}{c}\mathbf{0 , 2 5} \\
2,72 \mathrm{a} \\
2,83 \mathrm{a} \\
\end{array}$} & \multirow{3}{*}{$\begin{array}{c}\mathbf{0 , 5 0} \\
2,79 \mathrm{a} \\
2,93 \mathrm{a} \\
\end{array}$} & \multirow{2}{*}{$\begin{array}{r}\mathbf{0 , 7 5} \\
2,77 \mathrm{a}\end{array}$} & \multirow{2}{*}{$\begin{array}{c}\mathbf{1 , 0 0} \\
2,80 \mathrm{~b}\end{array}$} & \multirow{3}{*}{$\begin{array}{c}\mathbf{1 , 2 5} \\
2,75 \mathrm{a} \\
2,90 \mathrm{a}\end{array}$} & & \\
\hline \multirow{6}{*}{$\mathrm{N}$} & Folha & Solo & & & & & & & & \\
\hline & THina & Foliar & & & & $2,93 \mathrm{a}$ & $3,07 \mathrm{a}$ & & & \\
\hline & Caule & Solo & $0,88 \mathrm{a}$ & $0,87 \mathrm{~b}$ & $1,04 \mathrm{a}$ & $0,98 \mathrm{a}$ & $0,98 \mathrm{a}$ & $0,91 \mathrm{~b}$ & & \\
\hline & & Foliar & $0,98 \mathrm{a}$ & $1,05 \mathrm{a}$ & $1,06 \mathrm{a}$ & $1,10 \mathrm{a}$ & $1,07 \mathrm{a}$ & $1,22 \mathrm{a}$ & 2,78 & 13,13 \\
\hline & Kalz & Solo & $1,09 \mathrm{a}$ & $1,02 \mathrm{a}$ & $1,15 \mathrm{a}$ & $0,96 \mathrm{a}$ & $1,12 \mathrm{a}$ & $0,95 \mathrm{~b}$ & & \\
\hline & Kalz & Foliar & $1,15 \mathrm{a}$ & $1,16 \mathrm{a}$ & $1,24 \mathrm{a}$ & $1,13 \mathrm{a}$ & $1,14 \mathrm{a}$ & $1,28 \mathrm{a}$ & 5,90 & 11,66 \\
\hline \multirow{6}{*}{$\mathrm{P}$} & & Solo & $0,56 \mathrm{a}$ & $0,57 \mathrm{a}$ & $0,58 \mathrm{a}$ & $\overline{0,63 \mathrm{a}}$ & $0,61 \mathrm{a}$ & $0,60 \mathrm{a}$ & & \\
\hline & Foina & Foliar & $0,59 \mathrm{a}$ & $0,60 \mathrm{a}$ & $0,61 \mathrm{a}$ & $0,62 \mathrm{a}$ & $0,62 \mathrm{a}$ & $0,61 \mathrm{a}$ & 10,56 & 7,55 \\
\hline & Caule & Solo & $0,36 \mathrm{a}$ & $0,35 \mathrm{a}$ & $0,40 \mathrm{a}$ & $0.38 \mathrm{a}$ & $0.40 \mathrm{a}$ & $0,47 \mathrm{a}$ & & \\
\hline & & Foliar & $0,41 \mathrm{a}$ & $0,38 \mathrm{a}$ & $0,48 \mathrm{a}$ & $0,46 \mathrm{a}$ & $0,45 \mathrm{a}$ & $0,49 \mathrm{a}$ & $1 \cap 07$ & 1527 \\
\hline & Karz & Solo & $0,38 \mathrm{a}$ & $0,41 \mathrm{a}$ & $0,52 \mathrm{a}$ & $0,45 \mathrm{~b}$ & $0,41 \mathrm{a}$ & $0,35 \mathrm{~b}$ & & \\
\hline & Naiz & Foliar & $0,44 \mathrm{a}$ & $0,52 \mathrm{a}$ & $0,54 \mathrm{a}$ & $0,61 \mathrm{a}$ & $0,53 \mathrm{a}$ & $0,53 \mathrm{a}$ & 9,80 & 22,68 \\
\hline \multirow{6}{*}{ K } & & & $5,59 \mathrm{a}$ & $5,05 \mathrm{a}$ & $5,86 \mathrm{a}$ & $\overline{5,50 \mathrm{a}}$ & $6,05 \mathrm{a}$ & $5,61 \mathrm{a}$ & & \\
\hline & Folha & Foliar & $5,50 \mathrm{a}$ & $4,91 \mathrm{a}$ & $5,52 \mathrm{a}$ & $5,65 \mathrm{a}$ & $5,67 \mathrm{a}$ & $5,59 \mathrm{a}$ & 8,36 & 14,39 \\
\hline & Caule & Solo & $4,17 \mathrm{a}$ & $3,50 \mathrm{a}$ & $5,11 \mathrm{a}$ & $4,47 \mathrm{a}$ & $5,20 \mathrm{a}$ & $3,54 \mathrm{a}$ & & \\
\hline & & Foliar & $3,58 \mathrm{a}$ & $4,41 \mathrm{a}$ & $4,67 \mathrm{a}$ & $3,90 \mathrm{a}$ & $3,28 \mathrm{~b}$ & $4,41 \mathrm{a}$ & 17,29 & 18,88 \\
\hline & Ka1z & Solo & $2,94 \mathrm{a}$ & $2,92 \mathrm{a}$ & $3,41 \mathrm{a}$ & $2,77 \mathrm{a}$ & $2,98 \mathrm{a}$ & $1,86 \mathrm{~b}$ & & \\
\hline & Kalz & Foliar & $3,13 \mathrm{a}$ & $3,23 \mathrm{a}$ & $3,65 \mathrm{a}$ & $2,57 \mathrm{a}$ & $2,94 \mathrm{a}$ & $3,58 \mathrm{a}$ & 29,65 & 18,40 \\
\hline \multirow{6}{*}{$\mathrm{Ca}$} & & Solo & $0,97 \mathrm{a}$ & $0,94 \mathrm{a}$ & 0,99 a & $1,02 \mathrm{a}$ & $0,98 \mathrm{a}$ & $1,00 \mathrm{a}$ & & \\
\hline & Folna & Foliar & $0,92 \mathrm{a}$ & $0,93 \mathrm{a}$ & $0,91 \mathrm{a}$ & $1,00 \mathrm{a}$ & $0,93 \mathrm{a}$ & $0,94 \mathrm{a}$ & 12,71 & 6,73 \\
\hline & Caule & Solo & $0,20 \mathrm{~b}$ & $0,29 a$ & $0,32 \mathrm{a}$ & $0,30 \mathrm{a}$ & $0,32 \mathrm{a}$ & $0,33 \mathrm{a}$ & & \\
\hline & & Foliar & $0,29 \mathrm{a}$ & $0,28 \mathrm{a}$ & $0,33 \mathrm{a}$ & $0,34 \mathrm{a}$ & $0,34 \mathrm{a}$ & $0,35 \mathrm{a}$ & 12,04 & 16,21 \\
\hline & & Solo & $0,36 \mathrm{a}$ & $0,34 \mathrm{a}$ & $0,35 \mathrm{a}$ & $0,32 \mathrm{a}$ & $0,41 \mathrm{a}$ & $0,33 \mathrm{a}$ & & \\
\hline & Kaiz & Foliar & $0,39 \mathrm{a}$ & $0,36 \mathrm{a}$ & $0,38 \mathrm{a}$ & $0,36 \mathrm{a}$ & $0,40 \mathrm{a}$ & $0,39 \mathrm{a}$ & 15,55 & 12,53 \\
\hline \multirow{6}{*}{$\mathrm{Mg}$} & Folha & Solo & $0,39 a$ & $0,40 \mathrm{a}$ & $0,36 \mathrm{a}$ & $0,43 \mathrm{a}$ & $0,42 \mathrm{a}$ & $0,42 \mathrm{a}$ & & 8,19 \\
\hline & f Unia & Foliar & $0,39 \mathrm{a}$ & $0,39 \mathrm{a}$ & $0,40 \mathrm{a}$ & $0,39 \mathrm{a}$ & $0,38 \mathrm{a}$ & $0,38 \mathrm{a}$ & 11,97 & 8,19 \\
\hline & Caule & Solo & $0,11 \mathrm{~b}$ & $0,14 \mathrm{a}$ & $0,15 \mathrm{a}$ & $0.15 \mathrm{a}$ & $0.16 \mathrm{a}$ & $0.16 \mathrm{a}$ & & \\
\hline & Cuiv & Foliar & $0,15 \mathrm{a}$ & $0,14 \mathrm{a}$ & $0,17 \mathrm{a}$ & $0,17 \mathrm{a}$ & $0,17 \mathrm{a}$ & $0,18 \mathrm{a}$ & 12,95 & 15,27 \\
\hline & Karz & Solo & $0,14 \mathrm{a}$ & $0,13 \mathrm{a}$ & $0,16 \mathrm{a}$ & $0,12 \mathrm{~b}$ & $0,15 \mathrm{~b}$ & $0,12 \mathrm{~b}$ & & \\
\hline & Kalz & Foliar & $0,15 \mathrm{a}$ & $0,16 \mathrm{a}$ & $0,16 \mathrm{a}$ & $0,15 \mathrm{a}$ & $0,18 \mathrm{a}$ & $0,16 \mathrm{a}$ & 10,25 & 13,79 \\
\hline \multirow{6}{*}{$\mathrm{s}$} & Folha & Solo & $0,24 \mathrm{a}$ & $0,23 \mathrm{a}$ & $0,23 \mathrm{a}$ & $0,25 \mathrm{a}$ & $0,22 \mathrm{a}$ & $0,25 \mathrm{a}$ & 16,37 & 7,24 \\
\hline & 1 Unia & Foliar & $0,23 \mathrm{a}$ & $0,24 \mathrm{a}$ & $0,24 \mathrm{a}$ & $0,25 \mathrm{a}$ & $0,24 \mathrm{a}$ & $0,24 \mathrm{a}$ & & \\
\hline & Caule & Solo & $0,09 \mathrm{a}$ & $0,11 \mathrm{a}$ & $0,12 \mathrm{a}$ & $0,12 \mathrm{a}$ & $0,12 \mathrm{a}$ & $0,13 \mathrm{a}$ & 18,53 & 17,29 \\
\hline & & Foliar & $0,11 \mathrm{a}$ & $0,12 \mathrm{a}$ & $0,14 \mathrm{a}$ & $0,15 \mathrm{a}$ & $0,13 \mathrm{a}$ & $0,13 \mathrm{a}$ & & \\
\hline & Kayz & Solo & $0,17 \mathrm{a}$ & $0,18 \mathrm{a}$ & $0,18 \mathrm{a}$ & $0,17 \mathrm{a}$ & $0,18 \mathrm{a}$ & $0,17 \mathrm{a}$ & 9,01 & 8,46 \\
\hline & & Foliar & $0,19 a$ & $0,20 \mathrm{a}$ & $0,20 \mathrm{a}$ & $0,19 \mathrm{a}$ & $0,19 \mathrm{a}$ & $0,20 \mathrm{a}$ & & \\
\hline \multirow{6}{*}{$\mathrm{Na}$} & Folha & Solo & $0,34 \mathrm{a}$ & $0,33 \mathrm{a}$ & $0,32 \mathrm{a}$ & $0,34 \mathrm{a}$ & $0,33 \mathrm{a}$ & $0,32 \mathrm{a}$ & 8,30 & 3,89 \\
\hline & 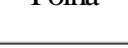 & Foliar & $0,34 \mathrm{a}$ & $0,34 \mathrm{a}$ & $0,33 \mathrm{a}$ & $0,34 \mathrm{a}$ & $0,35 \mathrm{a}$ & $0,34 \mathrm{a}$ & & \\
\hline & Caule & Solo & $0,51 \mathrm{a}$ & $0,46 \mathrm{a}$ & $0,46 \mathrm{a}$ & $0,47 \mathrm{a}$ & $0,50 \mathrm{a}$ & $0,49 \mathrm{a}$ & 9,51 & 11,82 \\
\hline & & Foliar & $0,50 \mathrm{a}$ & $0,49 \mathrm{a}$ & $0,52 \mathrm{a}$ & $0,54 \mathrm{a}$ & $0,53 \mathrm{a}$ & $0,56 \mathrm{a}$ & & \\
\hline & Kaiz & Solo & $0,47 \mathrm{a}$ & $0,46 \mathrm{a}$ & $0,47 \mathrm{a}$ & $0,43 \mathrm{~b}$ & $0,47 \mathrm{~b}$ & $0,42 \mathrm{~b}$ & 9,19 & 12,72 \\
\hline & Navz & Foliar & $0,55 \mathrm{a}$ & $0,51 \mathrm{a}$ & $0,56 \mathrm{a}$ & $0,55 \mathrm{a}$ & $0,70 \mathrm{a}$ & $0,62 \mathrm{a}$ & & \\
\hline
\end{tabular}

* Nas colunas, médias seguidas pela mesma letra, dentro de cada característica, não diferem entre si pelo teste Tukey a $5 \% \mathrm{~d}$ e probabilidade. ${ }^{1}$ Parcela; e 2 Subparcela. 
luição do $\mathrm{N}$ na maior MSF produzida. O efeito indireto é uma hipótese que encontra suporte no fato de que a quantidade de $\mathrm{N}$ veiculada na maior concentração $(1,25 \%)$ foi de apenas 1.209,6 $\mathrm{g}$ de $\mathrm{N} \mathrm{ha}^{-1}$, portanto, com pequena probablidade de proporcionar respostas significativas no teor desse elemento na planta.

Os teores de $\mathrm{P}, \mathrm{K}, \mathrm{Ca}, \mathrm{Mg}$, S e Na na MSF não apresentaram diferenças significativas entre vias de aplicação (Tabela 1). Também não houve efeito de concentrações da urina, aplicada via solo ou via foliar, sobre teores desses elementos na MSF. Os valores médios foram, em dag $\mathrm{kg}^{-1}$, de 0,61 e 0,59 (P); 5,61 e 5,48 (K); 0,99 e 0,94 (Ca); 0,40 e 0,39 (Mg); 0,239 e 0,237 (S); e 0,34 e 0,33 (Na).

Maiores teores de $\mathrm{Zn}$ (urina a $0,75 \%$ ), Fe (urina a $1,0 \%$ ) e Mn (urina a 0,25; 0,75 e 1,25\%) foram obtidos na MSF quando da aplicação da solução via solo, em comparação à aplicação via foliar, ocorrendo o inverso com $\mathrm{Cu}$ (urina a 0,25\%), sem diferença quanto aos teores de B (Tabela 2). Entretanto, não houve efeito da aplicação de urina nas concentrações desses micronutrientes. Os teores médios foram, em mg kg-1 de 106,7 e 109,5 (Zn); 351,43 e 308,0 (Fe); 383,27 e 322,7 (Mn); 7,27 e 7,46 (Cu); e 36,53 e 36,44 (B), respectivamente.

Com base nos valores de referência para interpretação dos resultados de análise foliar preconizados por Martinez et al. (1999), pode-se inferir, com relação aos teores médios de N, P, K, Ca, Mg e S (Tabela 1) e de Zn, Fe, Mn, Cu e B (Tabela 2), que: teores de N, P, K e Ca apresentaram-se inferiores aos valores referenciais de 4,0;0,80; 7,0; e 1,54 dag $\mathrm{kg}^{-1}$, respectivamente; $\mathrm{Mg}$ encontrou-se similar ao valor referencial, que 6 de $0,40 \mathrm{dag} \mathrm{kg}^{-1} ; \mathrm{S}$ foi ligeiramente superior ao valor de referência, que 6 de 0,19 dag $\mathrm{kg}^{-1}$; Cu e B foram inferiores aos valores de referência, 15 e $80 \mathrm{mg} \mathrm{kg}^{-1}$; $\mathrm{Zn}$ encontrou-se dentro da faixa de referência estabelecida, que 6 de 25 a $250 \mathrm{mg} \mathrm{kg}^{-1 ;}$ e os de Fe e Mn foram superiores às faixas de referências de 50 a 200 e de 50 a $250 \mathrm{mg} \mathrm{kg}^{-1}$, respectivamente.

Quanto ao $\mathrm{Na}$, o teor foi cerca de 10 vezes superior aos encontrados por Furlani et al. (1978) em cultivares de alface, que variou de 0,035 a $0,042 \mathrm{dag} \mathrm{kg}^{-1}$. Esse valor elevado pode ser atribuído à concentração de Na na urina. Santos (1995) também observou valores elevados de Na em cultivares de alface ao utilizar doses de at6 52,5 $\mathrm{t} \mathrm{ha}^{-1}$ de MS de composto orgânico à base de lixo urbano. Segundo Malavolta (1981), em alface o nível de Na de 0,045\% na parte a6rea 6 considerado fitotóxico; todavia Furlani et al. (1978) consideram normal o teor de $0,042 \%$ de $\mathrm{Na}$.

$\mathrm{O} \mathrm{Na}$, dada a sua característica de alterar o potencial osmótico, pode ser um elemento importante associado ao ganho de mat6ria fresca. Contudo, o uso de urina de vaca em alface conduzida no sistema orgânico é merecedor de maiores estudos, pois, embora a concentração encontrada de 0,34 dag $\mathrm{kg}$ seja potencialmente fitotóxica, não foram manifestados esses sintomas no primeiro cultivo.
Comparados aos resultados encontrados em alface 'Verônica' por Turazi et al. (2006), os teores de Zn (67,2 a $100,4)$ e B $\left(32,0\right.$ a $\left.33,8 \mathrm{mg} \mathrm{kg}^{-1}\right)$ foram similares, todavia bem inferiores para $\mathrm{Fe}(113,6$ a 204,2) e $\mathrm{Mn}(27,4$ a 115,8 $\mathrm{mg} \mathrm{kg}^{-1}$ ) (Tabela 2).

A ausência de efeito da aplicação de urina sobre os teores de N, P, K, Ca, Mg, S, Na, Zn, Fe, Mn, Cu e B na MSF foi devida, provavelmente, às pequenas quantidades desses elementos veiculados nas soluções e ao possível efeito de diluição desses na maior quantidade de MSCA produzida, além da fertilidade natural do solo e da adubação orgânica aplicada. Quanto ao fato de, em algumas concentrações, ocorrer efeito da via de aplicação sem um padrão de comportamento definido é difícil estabelecer hipóteses explicativas. É possível que haja um efeito indireto da urina.

Utilizando doses de 30 a $150 \mathrm{t} \mathrm{ha}^{-1}$ de esterco bovino na alface 'Elba', Pôrto (2006) verificou aumento nos teores de $\mathrm{N}, \mathrm{P}, \mathrm{K}$ e $\mathrm{Mg}$, obtendo, na dose máxima, teores de 6,7; 1,2; 6,3; e 0,5 dag $\mathrm{kg}^{-1} \mathrm{MSF}$, respectivamente; todavia, não observou efeito para o Ca que apresentou valor m6dio de 2,2 dag $\mathrm{kg}^{-1} \mathrm{MSF}$. Os teores de $\mathrm{S}$ verificados nas folhas de alface cv. Verônica por Turazi et al. (2006) foram de 0,30 a 0,46 dag $\mathrm{kg}^{-1}$ MSF. No presente trabalho, os teores de N, P, K, Ca, Mg e S na MSF (Tabela 1) foram bem inferiores aos encontrados por esses autores, o que pode ser atribuído ao cultivar, clima, solo e à adubação.

As plantas que receberam soluções de urina via foliar nas concentrações 0,25 e $1,25 \%$ apresentaram maiores teores de $\mathrm{N}$ na massa de mat6ria seca do caule (MSC) em relação à aplicação dessas mesmas concentrações via solo. A aplicação via solo a $1,0 \%$ proporcionou maior teor de K na MSC (Tabela 1). Tanto para $\mathrm{N}$ quanto para $\mathrm{K}$ não houve efeito de concentrações de urina. Os teores médios foliares foram de 0,94 e 1,08 dag kg-1 para $\mathrm{N}$ e de 4,33 e 4,04 dag $\mathrm{kg}^{-1}$ para $\mathrm{K}$ nas aplicações vias solo e foliar, respectivamente.

Os teores de $\mathrm{P}, \mathrm{Ca}, \mathrm{Mg}, \mathrm{S}$ e $\mathrm{Na}$ na MSC não apresentaram diferenças significativas entre vias de aplicação (Tabela 1); também não houve efeito de concentrações. Os teores médios foliares, nas aplicações vias solo e foliar, foram de 0,40 e 0,45(P); 0,29 e 0,32 (Ca); 0,15 e 0,16 (Mg); 0,12 e $0,13(\mathrm{~S})$; e 0,48 e $0,52(\mathrm{Na}) \mathrm{dag}_{\mathrm{kg}}{ }^{-1}$.

Os teores de Zn na MSC (urina a 0,50 e 1,0\%) foram maiores quando a solução foi aplicada via foliar, comparados à aplicação via solo. Quanto ao $\mathrm{Fe}$, a aplicação via solo (urina a $0,5 \%$ ) resultou em teor maior, ocorrendo o inverso para urina na concentração de $1,0 \%$. Nas concentrações de 0,25 e $1,0 \%$ de urina, o teor de Mn foi superior na aplicação via solo; na concentração de $0,25 \%$ de urina, a aplicação da solução via folhas resultou em teor maior de $\mathrm{B}$, enquanto o de $\mathrm{Cu}$ na MSC não apresentou diferenças significativas 
quanto às vias de aplicação (Tabela 2). Apesar desses efeitos de vias de aplicação, não houve efeito de concentrações sobre os teores de $\mathrm{Zn}, \mathrm{Fe}, \mathrm{Mn}, \mathrm{Cu}$ e B, as quais apresentaram, para aplicação vias foliar e solo, valores médios, em mg kg-1, de 123,16 e 109,02 (Zn); 156,25 e $160,20(\mathrm{Fe}) ; 52,57$ e 57,02 (Mn); 3,69 e 4,18 (Cu) e 32,65 e 36,30 (B).

Aumento dos teores de N, P, K e Mg na MSC da alface 'Elba' foi obtido por Pôrto (2006) quando utilizou $150 \mathrm{t} \mathrm{ha}^{-1}$ de esterco de bovino, porém sem haver incremento para Ca com teor $0,67 \mathrm{dag} \mathrm{kg}^{-1}$. Nessa dose, os teores obtidos foram de 5,8 (N); 2,6 (P); 6,1(K); e $0,34(\mathrm{Mg})$ dag $\mathrm{kg}^{-1}$. Os teores encontrados na MSC e também na MSF, neste trabalho, mesmo na maior concentração de urina utilizada $(1,25 \%)$, foram inferiores aos encontrados por Pôrto (2006).
Não foram encontradas informações sobre valores de referência para interpretação dos resultados de análise de tecidos de caule. Porém, constatou-se que as quantidades veiculadas nas concentrações e vias de aplicação não foram suficientes para promover efeitos significativos nos teores dos elementos avaliados na MSC.

Em algumas concentrações, plantas que receberam soluções de urina via foliar, comparadas às que a receberam via solo, apresentaram, na matéria seca de raiz (MSR), maiores teores de $\mathrm{N}(1,25 \%), \mathrm{P}(0,75$ e $1,25 \%), \mathrm{K}$ $(1,25 \%), \mathrm{Mg}$ e $\mathrm{Na}(0,75,1,0$ e $1,25 \%)$. Os teores de $\mathrm{N}, \mathrm{Ca}$, $\mathrm{Mg}$ e $\mathrm{S}$ na MSR não mostraram resposta às concentrações de urina tanto aplicada via solo quanto via foliar. Os teores médios, em dag $\mathrm{kg}^{-1}$, respectivos de 1,05 e 1,18 $(\mathrm{N}) ; 0,35$ e $0,38(\mathrm{Ca}) ; 0,14$ e $0,16(\mathrm{Mg})$; e 0,18 e $0,19(\mathrm{~S})$ (Tabela 1).

Tabela 2 - Valores médios dos teores de zinco ( $\mathrm{Zn})$, ferro $(\mathrm{Fe})$, manganês $(\mathrm{Mn})$, cobre $(\mathrm{Cu})$ e boro $(\mathrm{B})\left(\mathrm{mg} \mathrm{kg}^{-1}\right)$ na matéria seca de folhas, caule e raiz da alface 'Regina 2000' em razão da aplicação de concentração de soluções de urina de vaca vias solo e folhas

\begin{tabular}{|c|c|c|c|c|c|c|c|c|c|c|}
\hline \multirow{2}{*}{ Elementos } & \multirow{2}{*}{$\begin{array}{c}\text { Parte da } \\
\text { planta }\end{array}$} & \multirow{2}{*}{$\frac{\text { Via de }}{\text { aplicação }}$} & \multicolumn{6}{|c|}{ Concentração da solução de urina de vaca (\%) } & & \multirow{2}{*}{$\begin{array}{l}\mathrm{CV}^{2} \\
(\%)\end{array}$} \\
\hline & & & $\mathbf{0 , 0 0}$ & $\mathbf{0 , 2 5}$ & $\mathbf{0 , 5 0}$ & $\mathbf{0 , 7 5}$ & $\mathbf{1 , 0 0}$ & 1,25 & & \\
\hline \multirow{3}{*}{$\mathrm{Zn}$} & Folha & & $\begin{array}{l}104,47 \mathrm{a} \\
117,82 \mathrm{a}\end{array}$ & $\begin{array}{l}102,70 \mathrm{a} \\
116,25 \mathrm{a}\end{array}$ & $\begin{array}{l}96,65 \mathrm{a} \\
102,17 \mathrm{a}\end{array}$ & $\begin{array}{l}115,20 \mathrm{a} \\
97,95 \mathrm{~b}\end{array}$ & $\begin{array}{l}110,42 \mathrm{a} \\
115,57 \mathrm{a}\end{array}$ & $\begin{array}{l}110,52 \mathrm{a} \\
107,52 \mathrm{a}\end{array}$ & 8,43 & 10,32 \\
\hline & Caule & & $\begin{array}{l}106,10 \mathrm{a} \\
112,57 \mathrm{a}\end{array}$ & $\begin{array}{l}108,57 \mathrm{a} \\
113,27 \mathrm{a}\end{array}$ & $\begin{array}{l}105,30 \mathrm{~b} \\
135,50 \mathrm{a}\end{array}$ & $\begin{array}{l}104,02 \mathrm{a} \\
123,70 \mathrm{a}\end{array}$ & $\begin{array}{l}113,35 b \\
141,37 a\end{array}$ & $\begin{array}{l}116,75 \mathrm{a} \\
112,55 \mathrm{a}\end{array}$ & 2,92 & 17,86 \\
\hline & Raiz & & $\begin{array}{l}135,22 \mathrm{a} \\
153,52 \mathrm{a}\end{array}$ & $\begin{array}{l}147,02 \mathrm{a} \\
173,37 \mathrm{a}\end{array}$ & $\begin{array}{l}139,82 \mathrm{a} \\
154,77 \mathrm{a}\end{array}$ & $\begin{array}{l}112,43 \mathrm{~b} \\
184,02 \mathrm{a}\end{array}$ & $\begin{array}{l}147,37 \mathrm{a} \\
172,52 \mathrm{a}\end{array}$ & $\begin{array}{l}124,97 \mathrm{~b} \\
179,67 \mathrm{a}\end{array}$ & 20,36 & 11,27 \\
\hline \multirow{3}{*}{$\mathrm{Fe}$} & Folha & & $\begin{array}{l}290,67 \mathrm{a} \\
305,50 \mathrm{a}\end{array}$ & $\begin{array}{l}251,03 \mathrm{a} \\
259,67 \mathrm{a}\end{array}$ & $\begin{array}{l}364,43 \mathrm{a} \\
370,93 \mathrm{a}\end{array}$ & $\begin{array}{l}370,37 \mathrm{a} \\
272,60 \mathrm{a}\end{array}$ & $\begin{array}{l}521,70 \mathrm{a} \\
370,42 \mathrm{~b}\end{array}$ & $\begin{array}{l}310,36 \mathrm{a} \\
268,70 \mathrm{a}\end{array}$ & 30,86 & 16,85 \\
\hline & Caule & & $\begin{array}{l}95,92 \mathrm{a} \\
109,35 \mathrm{a}\end{array}$ & $\begin{array}{l}134,77 \mathrm{a} \\
142,10 \mathrm{a}\end{array}$ & $\begin{array}{c}279,37 \mathrm{a} \\
123,20 \mathrm{~b}\end{array}$ & $\begin{array}{l}168,32 \mathrm{a} \\
152,17 \mathrm{a}\end{array}$ & $\begin{array}{c}125,87 \mathrm{~b} \\
254,67 \mathrm{a}\end{array}$ & $\begin{array}{l}133,22 \mathrm{a} \\
179,67 \mathrm{a}\end{array}$ & 12,94 & 21,92 \\
\hline & Raiz & & $\begin{array}{l}22359,2 \mathrm{a} \\
14166,7 \mathrm{~b}\end{array}$ & $\begin{array}{l}21341,7 \mathrm{a} \\
13119,2 \mathrm{~b}\end{array}$ & $\begin{array}{l}11565,0 \mathrm{a} \\
14554,2 \mathrm{a}\end{array}$ & $\begin{array}{l}15504,2 \mathrm{a} \\
16420,8 \mathrm{a}\end{array}$ & $\begin{array}{l}16026,7 \mathrm{a} \\
8241,7 \mathrm{~b}\end{array}$ & $\begin{array}{l}22314,2 \mathrm{a} \\
13242,5 \mathrm{~b}\end{array}$ & 33,87 & 20,27 \\
\hline \multirow{3}{*}{ Mn } & Folha & & $\begin{array}{l}380,60 \mathrm{a} \\
409,55 \mathrm{a}\end{array}$ & $\begin{array}{l}413,45 \mathrm{a} \\
308,10 \mathrm{~b}\end{array}$ & $\begin{array}{l}313,67 \mathrm{a} \\
275,43 \mathrm{a}\end{array}$ & $\begin{array}{l}392,07 \mathrm{a} \\
248,79 \mathrm{~b}\end{array}$ & $\begin{array}{l}392,37 \mathrm{a} \\
400,70 \mathrm{a}\end{array}$ & $\begin{array}{l}407,45 \mathrm{a} \\
293,20 \mathrm{~b}\end{array}$ & 30,51 & 15,30 \\
\hline & Caule & & $\begin{array}{l}45,27 \mathrm{a} \\
59,27 \mathrm{a}\end{array}$ & $\begin{array}{l}64,52 \mathrm{a} \\
47,02 \mathrm{~b}\end{array}$ & $\begin{array}{l}57,52 \mathrm{a} \\
62,70 \mathrm{a}\end{array}$ & $\begin{array}{l}54,42 \mathrm{a} \\
56,40 \mathrm{a}\end{array}$ & $\begin{array}{l}61,02 \mathrm{a} \\
37,02 \mathrm{~b}\end{array}$ & $\begin{array}{l}59,37 \mathrm{a} \\
53,02 \mathrm{a}\end{array}$ & 15,30 & 18,60 \\
\hline & Raiz & & $\begin{array}{l}89,02 \mathrm{a} \\
84,35 \mathrm{a}\end{array}$ & $\begin{array}{l}94,12 \mathrm{a} \\
92,40 \mathrm{a}\end{array}$ & $\begin{array}{l}63,17 \mathrm{~b} \\
89,62 \mathrm{a}\end{array}$ & $\begin{array}{l}81,20 \mathrm{a} \\
87,97 \mathrm{a}\end{array}$ & $\begin{array}{l}103,82 \mathrm{a} \\
59,52 \mathrm{~b}\end{array}$ & $\begin{array}{l}105,35 \mathrm{a} \\
93,64 \mathrm{a}\end{array}$ & 15,31 & 16,33 \\
\hline \multirow{3}{*}{$\mathrm{Cu}$} & Folha & & $\begin{array}{l}7,20 \mathrm{a} \\
7,47 \mathrm{a}\end{array}$ & $\begin{array}{l}6,02 \mathrm{~b} \\
7,52 \mathrm{a}\end{array}$ & $\begin{array}{l}7,40 \mathrm{a} \\
7,52 \mathrm{a}\end{array}$ & $\begin{array}{l}8,20 \mathrm{a} \\
7,37 \mathrm{a}\end{array}$ & $\begin{array}{l}7,47 \mathrm{a} \\
7,35 \mathrm{a}\end{array}$ & $\begin{array}{l}7,35 \mathrm{a} \\
7,52 \mathrm{a}\end{array}$ & 8,82 & 13,28 \\
\hline & Caule & & $\begin{array}{l}1,60 \mathrm{a} \\
1,65 \mathrm{a}\end{array}$ & $\begin{array}{l}1,95 \mathrm{a} \\
3,32 \mathrm{a}\end{array}$ & $\begin{array}{l}4,45 \mathrm{a} \\
4,40 \mathrm{a}\end{array}$ & $\begin{array}{l}3,92 \mathrm{a} \\
4,92 \mathrm{a}\end{array}$ & $\begin{array}{l}4,92 \mathrm{a} \\
5,00 \mathrm{a}\end{array}$ & $\begin{array}{l}5,27 \mathrm{a} \\
5,77 \mathrm{a}\end{array}$ & 25,22 & 29,83 \\
\hline & Raiz & & $\begin{array}{l}20,20 \mathrm{a} \\
19,77 \mathrm{a}\end{array}$ & $\begin{array}{l}21,02 \mathrm{a} \\
23,20 \mathrm{a}\end{array}$ & $\begin{array}{l}22,20 \mathrm{a} \\
23,62 \mathrm{a}\end{array}$ & $\begin{array}{l}19,95 \mathrm{a} \\
22,32 \mathrm{a}\end{array}$ & $\begin{array}{l}22,77 \text { a } \\
19,45 \text { a }\end{array}$ & $\begin{array}{l}24,47 \mathrm{a} \\
21,77 \mathrm{a}\end{array}$ & 34,45 & 17,67 \\
\hline \multirow{3}{*}{ B } & Folha & & $\begin{array}{l}36,85 \mathrm{a} \\
38,55 \mathrm{a}\end{array}$ & $\begin{array}{l}35,82 \mathrm{a} \\
37,52 \mathrm{a}\end{array}$ & $\begin{array}{l}36,97 \mathrm{a} \\
36,50 \mathrm{a}\end{array}$ & $\begin{array}{l}36,20 \mathrm{a} \\
35,42 \mathrm{a}\end{array}$ & $\begin{array}{l}37,15 \mathrm{a} \\
36,17 \mathrm{a}\end{array}$ & $\begin{array}{l}36,17 \mathrm{a} \\
34,45 \mathrm{a}\end{array}$ & 10,71 & 5,11 \\
\hline & Caule & & $\begin{array}{l}30,95 \mathrm{a} \\
34,30 \mathrm{a}\end{array}$ & $\begin{array}{l}30,05 \mathrm{~b} \\
36,80 \mathrm{a}\end{array}$ & $\begin{array}{l}34,40 \mathrm{a} \\
39,25 \mathrm{a}\end{array}$ & $\begin{array}{l}31,00 \mathrm{a} \\
36,27 \mathrm{a}\end{array}$ & $\begin{array}{l}37,57 \mathrm{a} \\
35,72 \mathrm{a}\end{array}$ & $\begin{array}{l}31,90 \mathrm{a} \\
35,47 \mathrm{a}\end{array}$ & 10,95 & 10,65 \\
\hline & Raiz & & $\begin{array}{l}43,40 \mathrm{a} \\
46,00 \mathrm{a}\end{array}$ & $\begin{array}{l}46,42 \mathrm{a} \\
46,22 \mathrm{a}\end{array}$ & $\begin{array}{l}47,47 \mathrm{~b} \\
64,97 \mathrm{a}\end{array}$ & $\begin{array}{l}38,50 \mathrm{a} \\
40,42 \mathrm{a}\end{array}$ & $\begin{array}{l}44,70 \mathrm{a} \\
59,52 \mathrm{a}\end{array}$ & $\begin{array}{r}29,42 \mathrm{~b} \\
66,40 \mathrm{a}\end{array}$ & 9,94 & 23,30 \\
\hline
\end{tabular}

* Nas colunas, médias seguidas pela mesma letra, dentro de cada característica, não diferem entre si pelo teste Tukey a $5 \%$ de probabilidade. ${ }^{1}$ Parcela; e 2 Subparcela. 
Não houve efeito de concentrações na aplicação via foliar sobre os teores de P e K na MSR, cujos teores médios desses nutrientes foram, respectivamente, de 0,53 e $3,18 \mathrm{dag} \mathrm{kg}^{-1}$. Entretanto, quando a urina foi aplicada via solo foram observadas respostas quadráticas, com teores máximos de 0,47 (P) e 3,22 (K) dag kg-1 obtidos nas concentrag6es de urina de 0,58 e $0,45 \%$, respectivamente (Figura 2 A e B ). Com relação ao Na na MSR, não houve resposta às concentrag6es aplicadas via solo. Seu valor médio foi de $0,45 \mathrm{dag} \mathrm{kg}^{-1}$, entretanto, com a aplicação via folhas os teores de $\mathrm{Na}$ aumentaram linearmente com as concentrag6es, variando de 0,52 a 0,64 dag $\mathrm{kg}^{-1}$ (Figura 2 C).

Nas concentrações de 0,75 e 1,25\% de urina para Zn e de 0,50 e $1,25 \%$ de urina para $B$, maiores teores foram encontrados na MSR com a aplicação via foliar. Os teores de Fe não diferiram em relação às vias de aplicação, exceto nas concentrag6es de 0,5 e $0,75 \%$ de urina, para as quais foram observados maiores teores foliares quando a urina foi aplicada via solo. O Mn teve comportamento ambíguo, com maior teor quando da aplicação via folhas e no solo nas concentrag6es de 0,50 e de $1,0 \%$ de urina, respectivamente (Tabela $2 \mathrm{E}$ ). Não houve efeito de via de aplicação sobre o teor de $\mathrm{Cu}$.

Os teores de $\mathrm{Zn}, \mathrm{Cu}$ e B na MSR não apresentaram resposta às concentrag6es de soluções aplicadas, tanto via solo quanto foliar. As concentrações médias observadas (em mg kg-1) foram de 134,48 e 169,65 para $\mathrm{Zn}$; 21,77 e 21,69 para Cu; e 41,65 e 53,92 para B. Também os teores Fe e de Mn na MSR, quando da aplicação das solug6es via foliar, não mostraram resposta às concentrag6es, e os teores médios foram de 13.290,83 $\mathrm{mg} \mathrm{kg}^{-1}$ de $\mathrm{Fe}$ e $84,59 \mathrm{mg} \mathrm{kg}^{-1}$ de $\mathrm{Mn}$. No entanto, quando da aplicação via solo, os teores de ambos os elementos apresentaram respostas quadráticas, com menor valor de $14.114,5$ e 78,25 $\mathrm{mg} \mathrm{kg}^{-1}$, obtidos nas concentrag6es de $0,66 \%$ de urina para $\mathrm{Fe}$ e $0,49 \%$ de urina para $\mathrm{Mn}$ (Figura 2 D e E). Esses valores para teor de Fe sao bastante elevados, embora não tenham sido encontrados valores de referência na literatura. Além da possível contaminação das amostras com solo, o elevado teor desse nutriente no esterco aplicado poderá ter contribuído para com esses resultados.

Em alface 'Elba', Pôrto (2006) obteve teores máximos de 5,0; 2,1; 3,5; 0,88; e 0,25 $\mathrm{g} \mathrm{kg}^{-1}$ de MSR para N, P, K, Ca e $\mathrm{Mg}$, respectivamente, em função da aplicação das doses de esterco de bovino, valores esses bem superiores aos aqui encontrados.

$\mathrm{O}$ incremento linear do teor de $\mathrm{Na}$ na MSR com aumento das concentrag6es de urina nas solug6es aplicadas via foliar até poderia ser explicado pela maior veiculação de $\mathrm{Na}$ nas maiores concentrag6es, todavia isso não foi observado pela aplicação via solo (Figura 2 C). Possivelmente a interação do $\mathrm{Na}$ com o solo diminui a disponibilidade desse elemento para a ab- sorção radicular, diferentemente da aplicação sobre as folhas.

Quanto aos teores de K, Fe e Mn na MSR obtidos pela aplicação via solo, com pontos de máximo (K) e mínimo (Fe e $\mathrm{Mn}$ ), poderiam ser explicados por efeito competitivo

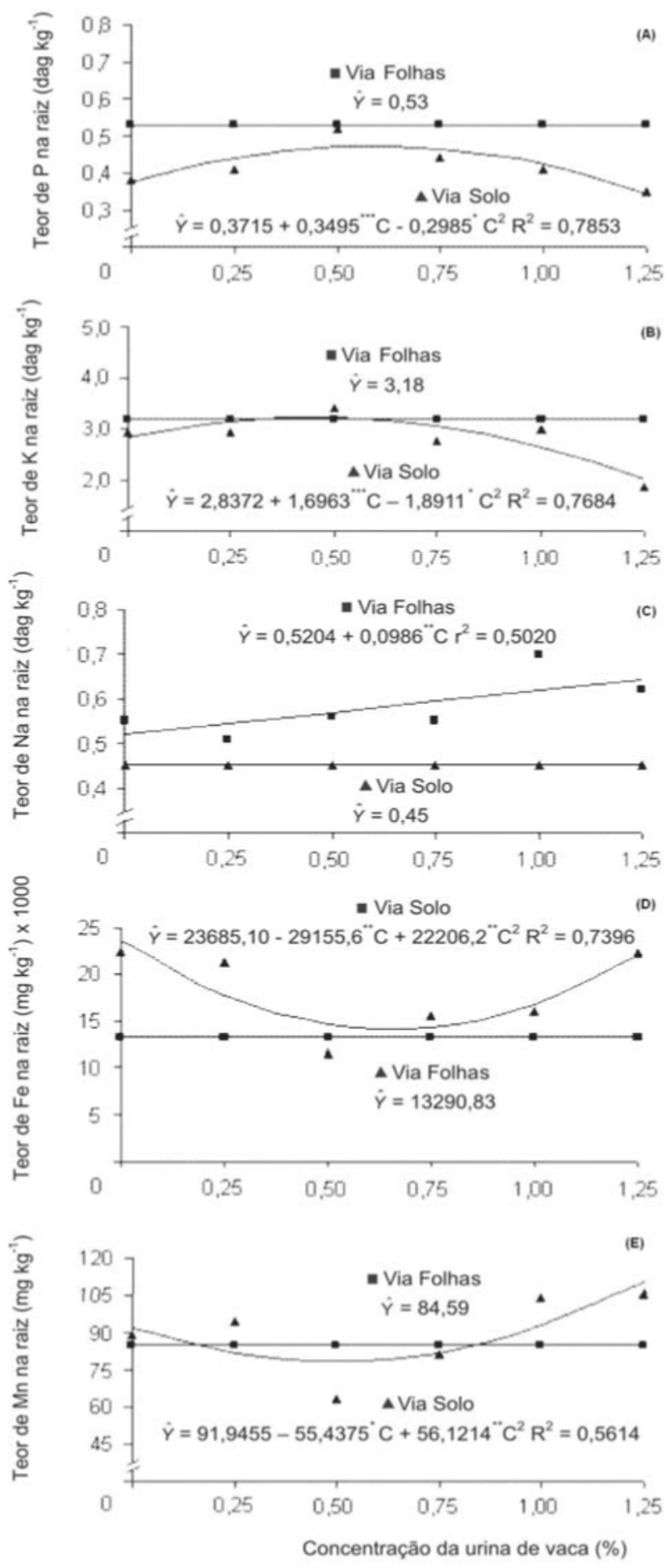

Figura 2 - Estimativa dos teores de $\mathrm{P}(\mathrm{A}), \mathrm{K}(\mathrm{B}), \mathrm{Na}(\mathrm{C}), \mathrm{Fe}$ (D) e Mn (E) na matéria seca de raiz da alface 'Regina 2000' em razãoda concentração de solug6es de urina de vaca aplicadas vias folhas (ם) e solo (A). **, * e ***: Significativos, respectivamente, a 1,5 e $10 \%$ de probabilidade. 
entre cátions por sítios de absorção. Todavia, o fato de em algumas concentrações ocorrerem efeito de via de aplicação para teores de $\mathrm{P}, \mathrm{K}, \mathrm{Na}, \mathrm{Fe}$ e Mn na MSR, sem um padrão de comportamento definido, dificulta o estabelecimento de hipóteses.

Apesar dos teores da maioria dos elementos analisados não terem apresentado respostas às concentrag6es das soluções de urina, verificou-se aumentos lineares na MSCA com as concentrações de urina aplicadas vias foliar $(25,98 \%)$ e solo $(35,38 \%)$. Portanto, as soluções de urina aplicadas exerceram efeito no crescimento da planta. Esse estímulo ao crescimento pode ser acompanhado pelo índice SPAD, que apresentou respostas lineares crescentes às concentrag6es de urina ao longo do ciclo. Porém, os incrementos na MSCA não podem ser justificados exclusivamente pelos nutrientes veiculados via soluções, visto que as quantidades totais de nutrientes veiculados, mesmo nas maiores concentrações, são pequenas para promover os aumentos observados.

De acordo com Nicouland et al. (1990) e Maia (2002), aumentos de rendimento de massa de matéria seca da parte aérea em trabalhos com adubação orgânica somente são observados com aplicag6es de doses elevadas. Os efeitos observados sobre o crescimento da alface com as solug6es de urina aplicadas são, provavelmente, devidos a fatores outros que não somente quantidade de nutrientes veiculados nas soluções. A ausência de resposta clara às concentrações de urina aplicadas para os elementos analisados leva a supor a existência de outro efeito que não nutricional, possivelmente de natureza hormonal, contido na urina de vaca, conforme sugerido por Gadelha (1999) e PESAGRO-RIO (2002), que tenha estimulado ocrescimento das plantas.

\section{CONCLUSÕES}

A urina de vaca aplicada via solo ou foliar tem efeito nos teores dos elementos minerais nas partes da planta, embora sem apresentar padrão definido.

Em concentrações relativamente baixas, a urina de vaca proporciona maior índice SPAD e incremento na massa de matéria seca das plantas.

Em razão da pequena quantidade de nutrientes veiculada nas soluções com urina de vaca, fatores outros que não a quantidade de elementos presentes nessas solug6es estimularam o crescimento das plantas.

\section{AGRADECIMENTOS}

À CAPES/PIQDTec/MEC, pela concessão de bolsa de mestrado ao primeiro autor. À Fundação de Amparo à Pesquisa do Estado de Minas Gerais (FAPEMIG), pelo financiamento da pesquisa e pela bolsa IC concedida a Aline da Silva Bhering (Projeto CAG APQ-0270-3.08-07).

\section{REFERENCIAS}

Achliya GS, Meghre VS, Wadodkar SG, Dorle AK (2004) Antimicrobial activity of different fractions of cow urine. Indian Journal of Natural Products, 20:14-18.

Alvarez VH \& Ribeiro AC (1999) Calagem. In: Ribeiro CA, Guimarães PTG \& Alvares VH (Eds.). Comissão de Fertilidade do Solo do Estado de Minas Gerais - Recomendag6es para uso de corretivos e fertilizantes em Minas Gerais - $5^{\mathrm{a}}$ Aproximação. Viçosa, CFSEMG. p.43-60.

Argenta G, Silva PRF da \& Bortolini CG (2001a) Teor de clorofila na folha como indicador do nível de $\mathrm{N}$ em cereais. Ciência Rural, 31:715-722.

Argenta G, Silva PRF da, Bartolini CG, Forsthofer EL \& Trieder ML (2001b) Relação da leitura do clorofilômetro com os teores de clorofila extraível e de nitrogênio na folha de milho. Revista Brasileira de Fisiologia Vegetal, 13:158-167.

Boemeke LR (2002) A urina de vaca como fertilizante, fortificante e repelente de insetos. Agroecologia e Desenvolvimento Rural Sustentável, 3:41-42.

Chapman SC \& Barreto HJ (1997) Using a chlorophyll meter to estimate specific leaf nitrogen of tropical maize during vegetative growth. Agronomy Journal, 89:557-562.

Faquin V (1994) Nutrição Mineral de plantas. Lavras, ESAL/ FAEPE. 227p.

Ferreira E (1995) A excreção de bovinos e as perdas de nitrogênio nas pastagens tropicais. Dissertação de Mestrado. Universidade Federal Rural do Rio de Janeiro. Seropédica, 114p.

Fontes PCR (2001) Diagnóstico do estado nutricional das plantas. Viçosa, UFV. 122p.

Furlani ACM, Furlani PR \& Bataglia DC (1978) Composição mineral de diversas hortaliças. Bragantia, 37:33-34.

Gadelha RSS (1999) Informag6es sobre a utilização de urina de vaca nas lavouras. Rio de Janeiro, PESAGRO. (Informativo mimeografado $\mathrm{s} / \mathrm{p}$.).

Gadelha RSS, Celestino RCA \& Shimoya A (2003) Efeito da utilização de urina de vaca na produção da alface. Pesquisa Agropecuária \& Desenvolvimento Sustentável, 1:179-182.

Guimaraes TG, Fontes PCR, Pereira PRG, Alvares V VH \& Monnerat PH (1999) Teores de clorofila determinados por medidor portátil e sua relagao com formas de nitrogênio em folhas de tomateiro cultivados em dois tipos de solo. Bragantia, $58: 209-216$.

Jarvis SC, Hatch DJ \& Roberts S (1989) The effects of grassland management in nitrogen losses from grazed award through ammonia volatilization; the relationship to excretal $\mathrm{N}$ returns from cattle. Journal Agricultural Science, 112:205-216.

Katayama M (1993) Nutrição e Adubação de alface, chicória e almeirão. In: Ferreira ME, Castellane PD \& Cruz MCP (Eds.) Nutrição e Adubação de Hortaliças. Piracicaba, Associação Brasileira para Pesquisa da Potassa e do Fosfato. p.141-148.

Lopes JC, Ribeiro LG, Araujo MG \& Beraldo MRSBS (2005) Produção de alface com doses de lodo de esgoto. Horticultura Brasileira, 23:143-147.

Maia SSS (2002) Uso de biofertilizante na cultura da alface. Dissertação de Mestrado. Escola Superior de Agricultura de Mossoró, Mossoró, 49p.

Malavolta E (1980) Elementos de nutrição mineral de plantas. São Paulo, Ceres. 251p.

Malavolta E (1981) Manual de química agrícola - adubos e adubação. São Paulo, Ceres. 478p.

Rev. Ceres, Viçosa, v. 57, n.4, p. 506-515, jul/ago, 2010 
Martinez HEP, Carvalho JG \& Souza RB (1999) Diagnose foliar. In: Ribeiro AC, Guimarães PT \& Alvares VH (Eds.) Comissão de Fertilidade do Solo do Estado de Minas Gerais - Recomendações para uso de corretivos e fertilizantes em Minas Gerais - 5a Aproximação. Viçosa, CFSEMG. p.143-168.

Neves OSC, Carvalho JG, Martins FAD, Pádua TRP \& Pinho RJ (2005) Uso do SPAD-502 na avaliação dos teores foliares de clorofila, nitrogênio, enxofre, ferro e manganês do algodoeiro herbáceo. Pesquisa Agropecuária Brasileira, 40:517-521.

Nicouland BAL, Meurer EJ \& Anghinoni I (1990) Rendimento e absorção de nutrientes por alface em função de calagem e adubação mineral e orgânica em solo "areia quartzoza hidromórfica". Horticultura Brasileira, 8:6-9.

Oliveira AP, Paes RA, Souza AP \& Dornelas CSM (2003) Rendimento de pimentão adubado com urina de vaca e NPK. In: 43 Congresso Brasileiro de Olericultura, Recife. Resumos, SOB. CD-ROM.

PESAGRO-RIO (2002) Urina de vaca: alternativa eficiente e barata. Rio de Janeiro, Documentos, n. 96. 8p.

Pôrto ML (2006) Produção, estado nutricional e acúmulo de ni- trato em plantas de alface submetidas à adubação nitrogenada e orgânica. Dissertação de Mestrado. Universidade Federal da Paraíba, Areia, 65p.

Santos IC (1995) Conteúdo de metais pesados, potássio e sódio e produção de cultivares de alface adubadas com composto de lixo urbano. Dissertação de Mestrado. Universidade Federal de Viçosa, $89 \mathrm{p}$.

Silva FC da (1999) Manual de análises químicas de solos, plantas e fertilizantes. Brasília, EMBRAPA. 370p.

Turazi CMV, Junqueira AMR, Oliveira AS \& Borgo LA (2006) A cúmulo de nitrato em alface em função da adubação, horário de colheita e tempo de armazenamento. Horticultura Brasileira, 24:65-70.

Villas Bôas RL, Passos JC, Fernandes DM, Büll LT; Cezar VRS \& Goto R (2004). Efeitos de doses de compostos orgânicos na produção de alface em dois solos sob ambiente protegido. Horticultura Brasileira, 22:28-34 